\title{
Prevalence and Factors Associated with Depression among HIV/AIDS-Infected Patients Attending ART Clinic at Jimma University Medical Center, Jimma, Southwest Ethiopia
}

\author{
Beyene Dorsisa (D), Gutema Ahimed, Susan Anand, and Tariku Bekela \\ School of Nursing and Midwifery, Jimma University, Ethiopia \\ Correspondence should be addressed to Beyene Dorsisa; beyenedo@gmail.com
}

Received 17 February 2020; Accepted 24 June 2020; Published 6 August 2020

Academic Editor: Lenin Pavón

Copyright (C) 2020 Beyene Dorsisa et al. This is an open access article distributed under the Creative Commons Attribution License, which permits unrestricted use, distribution, and reproduction in any medium, provided the original work is properly cited.

\begin{abstract}
Background. HIV is a chronic life-threatening illness and, like other similar chronic and stigmatizing illnesses, can be stressful to manage. Depression is a common mental health problem that deteriorates the quality of life of people with HIV/AIDS and found to be a strong predictor for noncompliance to antiretroviral therapy treatment. Therefore, epidemiological evidence on the factors associated with depression among patients with HIV/AIDS can contribute towards effective and efficient preventive health care strategies for this population. Objectives. To assess the prevalence and factors associated with depression among HIV/AIDS-infected patients attending ART clinic at Jimma University Medical Center, Jimma, Southwest Ethiopia, in 2018. Methods. This study followed an institution-based cross-sectional quantitative study design. A simple random sampling method yielded 303 participants who were interviewed from April to May 2018, using a pretested questionnaire, followed by their card review. The SPSS version 23 was used for bivariate analysis which was used to find out the significance of association. Variables that showed association in bivariate analysis at $p$ value $<0.25$ were entered to multivariable logistic regressions to control for confounders, and the significance of association was determined by $95 \%$ confidence interval and $p$ value $<0.05$. Results. The point prevalence of depression was $94(31 \%)$. Variables like sex (AOR $=0.510 \quad(95 \% \mathrm{CI}=0.264-0.986))$, marital status $(\mathrm{AOR}=3.610(95 \% \mathrm{CI}=1.649-7.901))$, opportunistic infection $(\mathrm{AOR}=3.122(95 \% \mathrm{CI}=1.700-5.733))$, and medication adherence $(\mathrm{AOR}=0.470(95 \% \mathrm{CI}=0.266-0.831))$ were significantly associated with depression. Conclusion and Recommendation. From the findings of this study, it is possible to conclude that depression was highly prevalent among people living with HIV/ADS. Sex, marital status, opportunistic infection, and medication adherence were found to be associated with depression and need attention from the health professional working in the ART clinic.
\end{abstract}

\section{Introduction}

Depression is one of the major mental health problems categorized under mood disorders and characterized by persistent experience of a depressed mood and loss of interest [1] and accompanied by symptoms like change in appetite, disrupted sleep patterns, increased or diminished activity level, impaired attention and concentration, and markedly decreased feelings of self-worth.

In severe forms, death wish or attempts to take one's life are present. Early diagnosis is essential, as in addition to the mental suffering, it causes significant social and occupational impairment [2]. HIV/AIDS is one of the global burden diseases, recognized as a serious public health problem and has spread throughout the world affecting all population [3].

It is a chronic and life-threatening illness and overwhelming to the individual [4]. Its life-threatening nature may induce fear of impending mortality. The medical squeal of HIV infection its associated opportunistic infections and side effects of antiretroviral treatment can mimic symptoms of depression (fatigue, concentration problems, somatic symptoms, decreased appetite, and weight loss [5]). When patients with HIV/AIDS develop depression, it accentuates 
the disease burden and is associated with poor health outcomes. It is also linked with poor antiretroviral therapy (ART) adherence resulting in loss of therapeutic effect, besides having a negative impact on the quality of life of people with HIV/AIDS. Unfortunately, depression is not diagnosed in majority of patients, and therefore, the condition goes untreated [6].

Reasons for high prevalence of depression among people living with HIV/AIDS (PLWHA) could be many [7]. Studies have revealed that depression is associated with different sociodemographic and health-related factors. It is persistently highly prevalent among the poor $[8,9]$. Studies in Botswana and Uganda, for example, revealed that depression was associated with food insecurity and the sex of the persons infected with HIV/AIDS [8-10]. The study carried out in Tigray, North Ethiopia, revealed that it was associated with the place of residence, economic status, and occupational status [11]. Depression tends to weaken a person's capacity for judgment, thereby predisposing for risky behaviors [12]. Recent data on the topic is lacking in Jimma; therefore, this study is aimed at determining the prevalence of depression and associated factors among PLWHA who are in ART follow-up at JUMC, Jimma.

Research evidence on the magnitude of depression among PLWHA is important to design more effective treatment programs for the management and prevention of its consequences and to improve their quality of life.

This study will provide research evidence for stakeholders on the magnitude of depression among PLWHA, in order to implement clinical and community-based intervention programs for the management and prevention of depression among PLWHA, aimed at improving their quality of life.

\section{Methods and Materials}

2.1. Study Area and Period. Jimma University Medical Center is found in Oromia region, southwest of Ethiopia in Jimma town, which is located $346 \mathrm{~km}$ to the southwest of Addis Ababa and provides health services for population in the town and the surrounding districts. In the town, there are different health facilities: four health centers, one general hospital and one specialized hospital currently, and one health center, and the two hospitals are giving ART service for people living with HIV/AIDS. In Jimma University Medical Center Hospital, there is a separate ART clinic at which care and follow-up are given for 3075 PLWHA. The study was conducted from April 3 till May 2018.

2.2. Study Design. Institutional-based cross-sectional study design was used.

2.3. Source Population. The source population were all PLWHA attending ART Clinic at Jimma University Medical Center.

2.4. Study Population. The study population were all PLWHA attending ART clinic at JUMC and who were included in to the sample

\subsection{Eligibility Criteria}

\subsubsection{Inclusion Criteria}

(i) Participants aged older than or equal to 18 years

(ii) Participants who are on routine appointment receiving ART treatment

\subsubsection{Exclusion Criteria}

(i) Bereavement within 3 months

(ii) Female patient in postpartum period

(iii) Those who have not done their CD4 count in six months preceding data collection

2.6. Sample Size Determination. The sample size was determined by using single population proportion formula. The following assumptions were made: marginal error $(d)$ that was tolerated in either sides of the true proportion to be $5 \%$, using $95 \%$ confidence level, $\alpha=0.05$, and the proportion of depression in HIV/AIDS patient taken from a research done in Fitche Zonal Hospital in 2017 $(P)=76.7 \%$. Those on steroid treatment [8]

$$
\begin{aligned}
& n=\frac{(Z(\alpha / 2))^{2} P(1-P)}{d^{2}}, \\
& n=\frac{(1.96)^{2} .767(1-.767)}{(.05)^{2}}=275
\end{aligned}
$$

where $n$ is the required sample size/minimum sample size required for the study.

$Z$ is the standard normal distribution $(Z=1.96)$ with confidence interval of $95 \%$, and $\alpha=0.05$.

$P$ is the prevalence/population proportion $(P=0.767)$.

$d$ is the desired absolute precision, a tolerable margin of error $(d=0.05)$ formula with $10 \%$ nonresponse rate which is 28 . Therefore, the final sample size is 303 .

2.7. Sampling Technique and Sampling Procedures. Simple random sampling technique was used to select the study subjects.

First, the list of patients was obtained from the database and registration logbook. Then, the lottery method was used to select each study subject.

2.8. Data Collection Instrument and Procedure. Data was collected using pretested interviewer-administered questionnaire, patient card review. Generally, questionnaire for this study contains 57 items and takes 30-45 minutes.

Part I. Socioeconomic characteristics were developed based on reviewed literature [8]. This contains 10 items with both open-ended and close-ended questions.

Part II. Behavioral factors are questions pertaining to substance use and sexual practices developed based on revied literature [41]. This contains 05 items with close-ended questions. 
Part III. Clinical factors are from some of the questionnaires adapted from another literature [36]. This contains 10 items with both open- and close-ended questions and Morisky Medication Adherence Scale. Eight questionnaires were standard which contains 08 items with close-ended questions; adherence was defined as adherent (high) with a Morisky Medication Adherence Scale score of 0 and nonadherent (medium, low) with a score of $1[44,45]$. The reliability of the instrument calculated using Cornbrash's alpha coefficient was 0.725 .

Part IV. Patient Health Questionnaire (PHQ-9) depressive symptom scale contains 09 items. It was a Likert scale with the following response options:Pateint health questionnaire (PHQ-9) depressive symptom scale have 09 items. $0=$ not at all, $1=$ several days, $2=$ more than half the days, and 3 = nearly every day. Classification of depression was measured by verbal responses of participants to PHQ-9 scale and expressed in scores. PHQ-9 was categorized as follows: severe depression: respondent with a score between 20 and 27; moderately severe depression: respondent with a score between 15 and 19; moderate depression: respondent with a score between 10 and 14; mild depression: respondent with a score between 5 and 9; minimal depression: respondent with a score between 1 and 4; and nondepressed respondent with score $0[46,47]$. The internal consistency of this instrument using Cornbrash's alpha was 0.883 .

Part V. Psychosocial factors: Oslo Social Support Scale contains 03 items by using close-ended questions. It was standard measured by verbal responses of participants to Oslo Social Support Scale and expressed in scores. Social support is categorized as follows: strong social support: respondent with a score between 12 and 14; moderate social support: respondent with a score between 9 and 11; and poor social support: respondent with a score between 3 and 8 [48]. The instrument showed reliability value 0.721 , by Cornbrash's alpha.

Perceived HIV related stigma contains 12 -item standard Likert scale with the following response options: $1=$ strongly disagree, $2=$ disagree, $3=$ agree, and $4=$ strongly agree. It contains personalized stigma, disclosure, public attitudes, and negative self-image. Perceived HIV-related stigma is assessed with a Likert scale[48]. The Cornbrash's alpha coefficient value was 0.648 .

2.9. Data Processing and Analyses. The data were analyzed by SPSS version 23 , using simple descriptive statistics.

The presence of crude association between the dependent variable with each independent variable was determined by bivariate logistic regression analysis. Variables that showed statistically significant association by bivariate analysis $(p<0.25)$ were further subjected to multivariable logistic regression analysis to control the confounding variables. The significance of association was determined at $95 \%$ confidence interval and $p$ value $<0.05$.

2.10. Data Quality Management. Two days of training were given to data collectors (four BSc nurses) and supervisors (two BSc nurses) on the objectives, clarity of tools, and overall data collection procedures to standardize interview procedures and reduce interviewers' bias. The final version of the questionnaire was translated into the Afan Oromo and Amharic language and once again retranslated in English language by bilingual experts, to check for language consistency of the tool.

The questionnaires were pretested on $5 \%$ of the sample at Shenen Gibe Hospital to determine clarity of the tool and feasibility of the study. At the end of each day, during data collection period, the collected data were checked for consistence and completeness.

2.11. Ethical Consideration. The study was conducted after the investigator gets an approval letter from the Institutional Review Board of Jimma University. Permission letter was provided to the hospital administrator before data collection. The purpose and procedure of data collection were clearly stated for the participants, and confidentiality and privacy were ensured. The right to refuse or withdraw from the study was respected. There were no risks or hazards to the participants, and there was no incentive for the participants. Those participants found to have suicide attempt and severe depression were referred to the psychotic clinics for early treatment.

\section{Results}

3.1. Socioeconomic Characteristics of the Participants. All the 303 patients who were selected for the study voluntarily responded to the interview, giving $100 \%$ response rate. More than half of the respondents, $159(52.5 \%)$, were females. Maximum representation was by patients who were in the productive age group 25-44 yrs, 202 (66.7\%) with mean age 39.36 ( $\mathrm{SD} \pm 9.63$ years); they were married $(125(41.3 \%))$ and lived with their families $(217(71.6 \%))$. Most had primary education $(127(41.9 \%))$ and were employed $(100(33 \%))$. Urban residents constituted the majority $(269(88.8 \%))$, and 203 (67\%) were earning less than 1380 ETB per month. They were of Oromo ethnicity (145 (47.9\%)), Orthodox Christians (121 (39.9\%)) with moderate social support (143 (47.2\%)) (Table 1).

3.2. Prevalence of Depression. Nearly one-third (94 (31\%)) of the participants were found to have depression, while 72 (24\%) had mild depression, 19 (6\%) had moderate depression, and $3(1 \%)$ were found to be with moderately severe depression (Figure 1).

3.3. Substance Use and Risky Behavior. Interview on the behavioral characteristics revealed that few numbers of the respondents (53 (17.5\%)) used alcohol, 7 (2.3\%) of the participants smoked tobacco, and 78 (25.7\%) of the participants chewed khat. Information on the sexual practices showed that $25(67.6 \%)$ reported inconsistent use of condom whereas $12(32.4 \%)$ never used a condom (Table 2).

3.4. Clinical Characteristics of the Participants. Most of the participants $(290(95.7 \%))$ were at HIV stage T1, 125 (41.3\%) had been diagnosed as HIV infected for the past 6- 
TABLE 1: Distribution of study participants by their socioeconomic characteristics, Jimma University Medical Center, April to May $2018(N=303)$.

\begin{tabular}{|c|c|c|}
\hline Characteristics & $N$ & $\%$ \\
\hline \multicolumn{3}{|l|}{ Sex } \\
\hline Male & 144 & 47.5 \\
\hline Female & 159 & 52.5 \\
\hline Total & 303 & 100 \\
\hline \multicolumn{3}{|l|}{ Age } \\
\hline $18-24$ & 13 & 4.3 \\
\hline $25-44$ & 202 & 66.7 \\
\hline $45-64$ & 80 & 26.4 \\
\hline$>65$ & 8 & 2.6 \\
\hline Total & 303 & 100 \\
\hline \multicolumn{3}{|l|}{ Marital status } \\
\hline Married & 125 & 41.3 \\
\hline Single & 42 & 13.9 \\
\hline Divorced & 74 & 24.4 \\
\hline Separated & 6 & 2.0 \\
\hline Widowed & 56 & 18.5 \\
\hline Total & 303 & 100 \\
\hline \multicolumn{3}{|l|}{ Living status } \\
\hline With family & 217 & 71.6 \\
\hline Alone & 53 & 17.5 \\
\hline With relatives & 33 & 10.9 \\
\hline Total & 303 & 100 \\
\hline \multicolumn{3}{|l|}{ Educational status } \\
\hline No education & 63 & 20.8 \\
\hline Primary school & 127 & 41.9 \\
\hline Secondary school & 42 & 13.8 \\
\hline Above secondary & 71 & 23.4 \\
\hline Total & 303 & 100 \\
\hline \multicolumn{3}{|l|}{ Occupation } \\
\hline Farmer & 18 & 5.9 \\
\hline Government employee & 100 & 33.0 \\
\hline Student & 12 & 4.0 \\
\hline Daily laborer & 91 & 30.0 \\
\hline Housewife & 68 & 22.4 \\
\hline Unemployed & 14 & 4.6 \\
\hline Total & 303 & 100 \\
\hline \multicolumn{3}{|l|}{ Residence } \\
\hline Rural & 34 & 11.2 \\
\hline Urban & 269 & 88.8 \\
\hline Total & 303 & 100 \\
\hline \multicolumn{3}{|l|}{ Monthly income } \\
\hline$<1380$ & 203 & 67.0 \\
\hline $1381-2872$ & 45 & 14.9 \\
\hline$>2872$ & 55 & 18.2 \\
\hline Total & 303 & 100 \\
\hline
\end{tabular}

TABle 1: Continued.

\begin{tabular}{lcc}
\hline Characteristics & $N$ & $\%$ \\
\hline Ethnicity & 145 & \\
Oromo & 82 & 47.9 \\
Amhara & 19 & 27.1 \\
Tigre & 26 & 6.3 \\
Gurage & 31 & 8.6 \\
Dawuro & 303 & 10.2 \\
Total & & 100 \\
Religion & 105 & \\
Muslim & 121 & 34.7 \\
Orthodox & 63 & 39.9 \\
Protestant & 14 & 20.8 \\
Catholic & 303 & 4.6 \\
Total & & 100 \\
Social support & 117 & \\
Poor support & 143 & 38.6 \\
Moderate support & 43 & 14.2 \\
Good support & 303 & 100 \\
Total & &
\end{tabular}

10 years, and $128(42.2 \%)$ had been on treatment since the last 6-10 yrs.

While most participants (226 (74.6\%)) had never been screened for depression prior to initiation of ART, 155 $(51.2 \%)$ received treatment with 1 e/Tdf-3tc-Nvp. Majority of the participants $(264(87.1 \%))$ did not experience side effect from ART and 218 (71.9\%) did not have opportunistic infection, $147(48.5 \%)$ had recent CD4 cell count which was between 200 and 499 cells $/ \mathrm{mm}^{3}$, and 228 (75.2\%) of the participants had never received food supplement from ARV treatment programmer. But more than half of the respondents (164 (54.1\%)) reported good adherence to ART (Table 3).

3.5. Aspects of Stigma. The HIV/AIDS-related stigma scale showed personal stigma mean score $6.23 \mathrm{SD} \pm 1.572$, disclosure mean score $7.49 \mathrm{SD} \pm 1.819$, public attitude mean score $5.78 \mathrm{SD} \pm 1.060$, and self-image mean score $5.88 \mathrm{SD} \pm 1.386$ (Table 4).

3.6. Factors Associated with Depression among People Living with HIVIAIDS. Among all the explanatory variables subjected to bivariate binary logistic regression analysis, sex of participant, marital status, occupation, social support, medication adherence, alcohol drinking, khat chewing, opportunistic infection, and CD4 count had $p$ value $<0.25$ and were further entered into multivariable analysis to control for confounding.

In multivariable logistic regression, four independent predictor variables (sex, marital status, opportunistic infection, and medication adherence) were found to be significantly associated with depression at $p$ value less than 0.05 . 


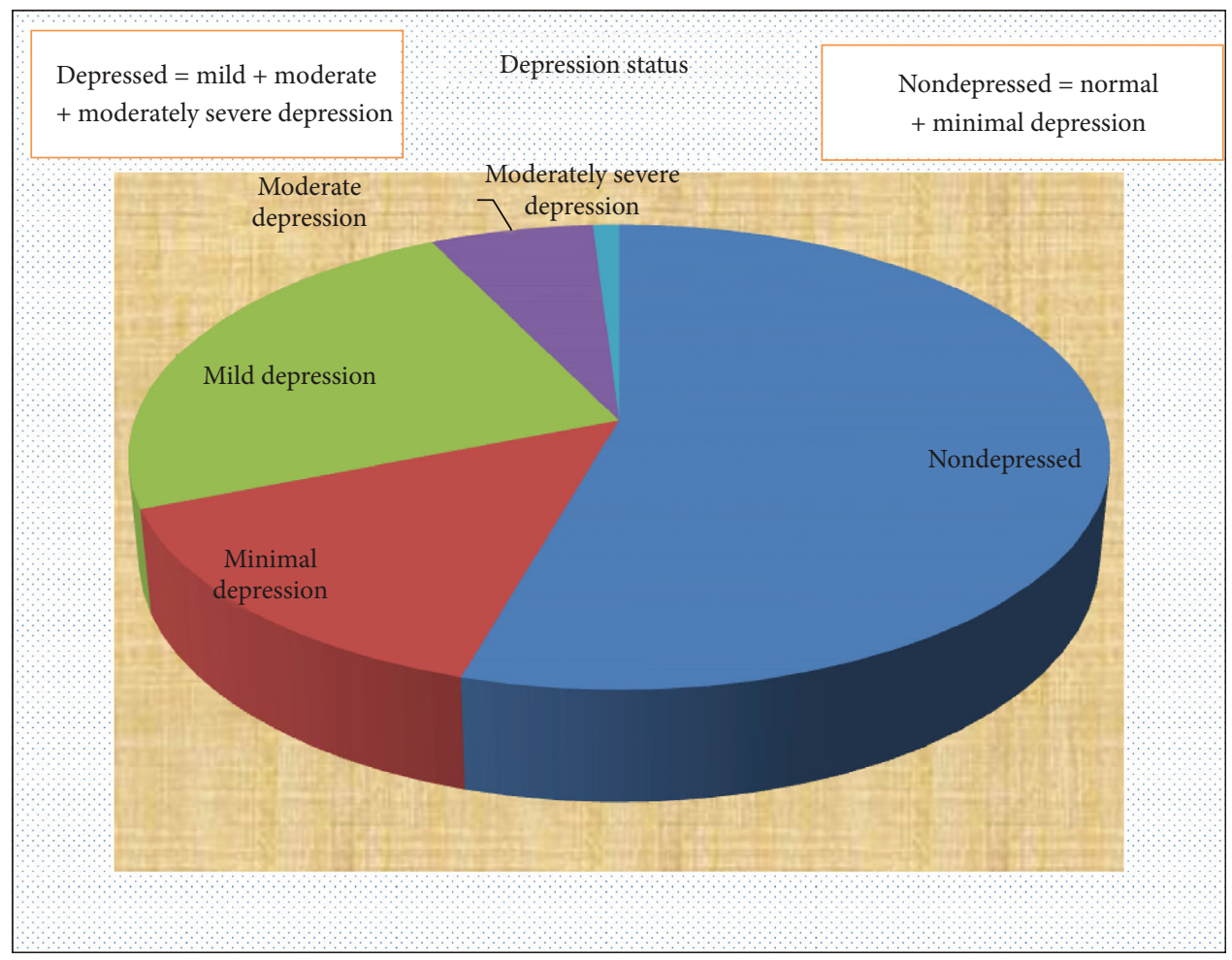

FIGURE 1: Prevalence of depression among study participants, Jimma University Medical Center, April to May $2018(N=303)$.

TABLE 2: Distribution of study participants by their behavioral characteristics, Jimma University Medical Center, April-May 2018 $(N=303)$.

\begin{tabular}{lcccc}
\hline \multirow{2}{*}{ Characteristics } & \multicolumn{4}{c}{$N=303$} \\
& Male & Female & Total & Percent \\
\hline Alcohol use & & & & \\
$\quad$ Yes & 28 & 25 & 53 & 17.5 \\
$\quad$ No & 116 & 134 & 250 & 82.5 \\
Tobacco use & & & & \\
$\quad$ Yes & 5 & 2 & 7 & 2.3 \\
$\quad$ No & 139 & 157 & 296 & 97.7 \\
Khat use & & & & \\
$\quad$ Yes & 44 & 34 & 78 & 25.7 \\
$\quad$ No & 100 & 125 & 225 & 74.3 \\
Unsafe sex practice & & & & \\
$\quad$ Yes & 22 & 15 & 37 & 12.2 \\
$\quad$ No & 122 & 114 & 266 & 87.8 \\
Condom utilization & & & & \\
$\quad$ Inconsistent condom use & 15 & 10 & 25 & 67.6 \\
$\quad$ Never use a condom & 1 & 3 & 4 & 32.7 \\
\hline
\end{tabular}

Susceptibility for depression was more among HIVinfected females (AOR: 0.510, 95\% CI: 0.264-0.986), widowed persons (AOR: 3.610, 95\% CI: 1.649-7.901), contracting opportunistic infections (AOR: 3.122, 95\% CI:
2.719-61.923), and poor medication adherence (AOR: 0.470, 95\% CI: 0.266-0.831) (Table 5).

\section{Discussion}

This study was conducted to investigate the prevalence of depression among PLWHA enrolled in ART and its association with sociodemographic, behavioral, clinical, and social support factor.

4.1. The Prevalence of Depression. This study revealed that the prevalence of depression among the study participants was $94(31 \%)$ and was lower than that of the studies conducted in Ethiopia at Debre Birhan (38.94\%) and in northern Showa (76.7\%) [41, 8]. Studies done in India showed that the prevalence of depression was $58.75 \%$ and $67.3 \%$ at different periods [7, 32] similarly in Brazil, Denmark, and north central Nigeria (42.3\%, $61 \%$, and $56.7 \%$, respectively) [29, 30, 33], but higher than the prevalence among patients at Hawassa, Ethiopia (24.5\%) [49].

The variations could be attributed to differences in sample size, instruments used to determine depression, and different geographical locations. Moreover, it is likely that responding by a face-to-face interview may have prompted the participants to give socially desirable answers. However, this very significant finding in the current study highlights the need for early diagnosis of depression in this vulnerable population. 
TABle 3: Distribution of study participants by their clinical characteristics, Jimma University Medical Center, April-May 2018 $(N=303)$.

\begin{tabular}{|c|c|c|}
\hline Characteristics & $N(n=303)$ & $\%$ \\
\hline \multicolumn{3}{|l|}{ Side effects of ART } \\
\hline None & 264 & 87.1 \\
\hline Sometimes & 29 & 9.6 \\
\hline Always & 10 & 3.3 \\
\hline \multicolumn{3}{|c|}{ Diagnosed with OIs in the past 6 months } \\
\hline None & 218 & 71.9 \\
\hline Once and twice or more & 85 & 28.1 \\
\hline \multicolumn{3}{|l|}{ Recent CD4 level } \\
\hline$<200$ & 7 & 2.3 \\
\hline $200-499$ & 147 & 48.5 \\
\hline$>500$ & 149 & 49.2 \\
\hline \multicolumn{3}{|l|}{ Chronic disease } \\
\hline Yes & 80 & 26.4 \\
\hline No & 223 & 73.6 \\
\hline \multicolumn{3}{|c|}{ Screened for depression prior to ART } \\
\hline Yes & 77 & 25.4 \\
\hline No & 226 & 74.6 \\
\hline \multicolumn{3}{|l|}{ Stage of HIV/ADS } \\
\hline $\mathrm{T} 1$ & 290 & 95.7 \\
\hline $\mathrm{T} 2$ & 13 & 4.3 \\
\hline \multicolumn{3}{|l|}{ Type of ART regimen } \\
\hline $1 \mathrm{c}$ & 81 & 26.7 \\
\hline $1 d$ & 30 & 9.9 \\
\hline $1 \mathrm{e}$ & 155 & 51.2 \\
\hline 1f & 28 & 9.2 \\
\hline $2 \mathrm{~h}$ & 9 & 3.0 \\
\hline \multicolumn{3}{|c|}{ Duration on HAART treatment (in months) } \\
\hline $4-40$ & 41 & 13.5 \\
\hline $41-80$ & 104 & 34.3 \\
\hline $81-120$ & 128 & 42.2 \\
\hline$>120$ & 30 & 9.9 \\
\hline \multicolumn{3}{|c|}{$\begin{array}{l}\text { Duration from diagnosis HIV infection } \\
\text { (in months) }\end{array}$} \\
\hline $4-40$ & 37 & 12.2 \\
\hline $41-80$ & 103 & 34.0 \\
\hline $81-120$ & 125 & 41.3 \\
\hline$>120$ & 38 & 12.5 \\
\hline \multicolumn{3}{|c|}{$\begin{array}{l}\text { Receive food supplement from ARV } \\
\text { treatment programmer }\end{array}$} \\
\hline Never & 228 & 75.2 \\
\hline Previously & 66 & 21.8 \\
\hline Currently & 9 & 3.0 \\
\hline \multicolumn{3}{|l|}{ Medication adherence } \\
\hline Good adherence & 164 & 54.1 \\
\hline Poor adherence & 139 & 45.9 \\
\hline
\end{tabular}

TABle 4: Distributions of study participants by their stigma characteristics, Jimma University Medical Center, April-May 2018 $(N=303)$.

\begin{tabular}{lccc}
\hline Characteristics & Mean & Standard deviation & Item \\
\hline Personal stigma & 6.23 & 1.572 & 3 \\
Disclosure & 7.49 & 1.819 & 3 \\
Public attitude & 5.78 & 1.060 & 3 \\
Self-image & 5.88 & 1.386 & 3 \\
\hline
\end{tabular}

4.2. Factors Associated with Depression. Research shows gender is closely associated with depression with women being more prone to depression. This study confirmed that HIV-infected males were $49 \%$ less likely to develop depression when compared to females. Similar findings were shown in studies from northern Showa, north central Nigeria, Tehran, and Hawassa $[8,33,37,49]$. Women in male-dominated societies are at the receiving end for all the misfortunes such as poverty, violence, discrimination, and single parenthood. Being diagnosed with HIV adds to this burden and makes them more vulnerable to depression than males. The findings are negated by the study at Harar region of Ethiopia [36].

This study found that the marital status of the HIVinfected person is a significant factor for comorbidity with depression. Widowhood predisposed a person nearly 4 times to develop depression when compared to those who had a stable marital life. The findings are in line with studies conducted in Harar and Hawassa (Ethiopia) $[36,37]$ and Tehran in Iran [49]. Unstable marital relationships and loss of partner predispose for depression, but presence of good social support can be a buffer against stress and depression.

Another major finding of this study was the risk for depression increased threefold when the person contracts opportunistic infections, which is in line with a study at Fiche, Ethiopia [8]. Opportunistic infections have synergistic effects on the disease progression and AIDS-related mortalities. Depression has an effect on immunosuppression, and immunosuppression inversely predisposes depression.

Good medication adherence can lower the risk for depression by more than half as revealed through this study and supported by similar studies in Addis Ababa, Ethiopia [42]. HIV-infected people often default on medication due to difficulty in accessing the health center, being forgetful and due to unpleasant side effects of antiretroviral therapy. This significant finding reemphasizes the need for creating awareness on medication compliance among HIV-infected people and providing supportive services for individuals on treatment.

It is perplexing that this study did not find a significant association between depression and social support, perceived stigma, substance use, and CD4 count among the respondents, contrary to available literature. The recent CD4 cell count of most participants in this study was between 200 and $499 \mathrm{cells} / \mathrm{mm}^{3}$. Moreover, the tendency to give socially desirable responses in an interview may be a reason for this contradiction. 
TABLE 5: Bivariate binary logistic regression analysis and multivariable logistic regression analysis of the respondents in JUMC, April to May 2018.

\begin{tabular}{|c|c|c|c|c|}
\hline \multirow{2}{*}{ Characteristics } & \multicolumn{2}{|c|}{ Depression } & \multirow{2}{*}{ COR $(95 \%$ CI $) p$ value } & \multirow{2}{*}{ AOR $(95 \%$ CI $) p$ value } \\
\hline & None & Depressed & & \\
\hline \multicolumn{5}{|l|}{$\overline{S e x}$} \\
\hline Male & 107 & 37 & $0.619(0.377-1.015) *$ & $0.510(0.264-0.986) * *$ \\
\hline Female & 102 & 57 & 1 & 1 \\
\hline \multicolumn{5}{|l|}{ Marital status } \\
\hline Married & 97 & 28 & 1 & 1 \\
\hline Single & 32 & 10 & $0.310(0.158-0.607) *$ & $0.889(0.318-2.486)$ \\
\hline Divorced & 46 & 28 & $0.336(0.139-0.811) *$ & $1.638(0.752-3.568)$ \\
\hline Separated & 97 & 28 & $0.654(0.323-1.322) *$ & $0.778(0.079-7.635)$ \\
\hline Widowed & 32 & 10 & $0.215(0.024-1.958) *$ & $3.610(1.649-7.901) * *$ \\
\hline \multicolumn{5}{|l|}{ Occupation } \\
\hline Farmer & 12 & 6 & 1 & 1 \\
\hline G. employee & 74 & 26 & $1.833(0.367-9.166)$ & $2.680(0.443-16.220)$ \\
\hline Student & 9 & 3 & $1.288(0.333-4.982)$ & $2.418(0.517-11.303)$ \\
\hline Daily laborer & 53 & 38 & $1.222(0.197-7.594)$ & $1.395(0.147-13.226)$ \\
\hline H. wife & 50 & 18 & $2.629(0.686-10.069) *$ & $3.757(0.800-17.642)$ \\
\hline Unemployed & 11 & 3 & $1.320(0.330-5.276)$ & $1.232(0.246-6.178)$ \\
\hline \multicolumn{5}{|l|}{ Alcohol use } \\
\hline Yes & 31 & 22 & $1.754(0.952-3.233) *$ & $1.590(0.715-3.537)$ \\
\hline No & 178 & 72 & 1 & 1 \\
\hline \multicolumn{5}{|l|}{ Khat use } \\
\hline Yes & 49 & 29 & $1.457(0.847-2.505) *$ & $1.482(0.717-3.063)$ \\
\hline No & 160 & 65 & 1 & 1 \\
\hline \multicolumn{5}{|l|}{ Diagnosed with OIs } \\
\hline None & 166 & 52 & 1 & 1 \\
\hline Once and twice or more & 43 & 42 & $0.321(0.189-0.543) *$ & $3.122(1.700-5.733) * *$ \\
\hline \multicolumn{5}{|l|}{ CD4 level } \\
\hline$<200$ & 5 & 2 & 1 & 1 \\
\hline $200-499$ & 93 & 54 & $1.168(0.218-6.274)$ & $0.860(0.119-6.192)$ \\
\hline$>500$ & 111 & 38 & $1.696(1.031-2.791)$ & $1.096(0.602-1.997)$ \\
\hline \multicolumn{5}{|l|}{ Medication adherence } \\
\hline Good adherence & 105 & 59 & $2.343(1.475-3.723) *$ & $0.470(0.266-0.831) * *$ \\
\hline Poor adherence & 60 & 79 & 1 & 1 \\
\hline \multicolumn{5}{|l|}{ Social support } \\
\hline Poor support & 66 & 51 & 1 & 1 \\
\hline Moderate support & 110 & 33 & $2.550(1.150-5.654) *$ & $1.956(0.785-4.871)$ \\
\hline Good support & 33 & 10 & $0.990(0.442-2.220)$ & $1.074(0.428-2.697)$ \\
\hline
\end{tabular}

NB: $* p<0.25, * * p<0.05,1=$ reference.

Individual's sex, marital status, opportunistic infections, and medication adherence were factors associated with risk of developing depression among people living with HIV/AIDS.

\section{Abbreviations}

AIDS: Acquired immune deficiency syndrome

AOR: $\quad$ Adjusted odds ratio
ART: $\quad$ Antiretroviral therapy

BDI: Beck Depression Inventory

BMI: $\quad$ Body mass index

CI: $\quad$ Confidence interval

COR: $\quad$ Crude odds ratio

ETB: $\quad$ Ethiopian birr

JUMC: Jimma University Medical Center

MMAS: Morisky Medication Adherence Scale

OIs: $\quad$ Opportunistic infections 
OR: $\quad$ Odds ratio

PHQ: $\quad$ Patient Health Questionnaires

PLWHA: People living with HIV/AIDS

SPSS: $\quad$ Statistical Package Software for Social Sciences

WHO: World Health Organization.

\section{Data Availability}

The data used to support the findings of this study are included within the article.

\section{Conflicts of Interest}

$\mathrm{BD}$ is a staff in the School of Nursing in the Institute of Health Jimma University, GA (BSc, MSc) is a lecturer of psychiatry in the Institute of Health Jimma University, SA is a professor (BSc, MSc, M. Phil, PhD) in Jimma University, and TB is a lecturer of the Midwifery Department at Jimma University. All authors are currently staff members in their respective departments in Jimma University. The authors declare that they have no competing interests.

\section{Authors' Contributions}

BD was involved in designing the study, data collection, data analysis, drafting, and critically reviewing the manuscript. Likewise, GA and SA were involved in designing the study, analysis of the data, and critically reviewing the manuscript. TB was involved in data collection, data analysis, and commenting on the manuscript. All authors read and approved the final manuscript. GA, SA, and TB are equal contributors.

\section{Acknowledgments}

We would like to acknowledge Jimma University for giving us the opportunity to do this research. We also acknowledge the data collectors and Jimma University Medical Center ART clinic. This study was funded by Jimma University in partial fulfillment of the requirement for Master of Science degree in adult health nursing.

\section{References}

[1] K. K. Lee, "Major depressive disorder and bipolar mood disorders," Encyclopedia of Social Work, pp. 1-30, 2016.

[2] M. Slot, M. Sodemann, C. Gabel, J. Holmskov, T. Laursen, and L. Rodkjaer, "Factors associated with risk of depression and relevant predictors of screening for depression in clinical practice: a cross-sectional study among HIV-infected individuals in Denmark," HIV Medicine, vol. 16, no. 7, pp. 393-402, 2015.

[3] Depression overviewhttps://www.nimh.nih.gov/health/topics/ depression/index.shtml.

[4] D. Goldberg, "The detection and treatment of depression in the physically ill," World Psychiatry, vol. 9, no. 1, pp. 16-20, 2010 .

[5] S. A. Safren, J. S. Gonzalez, D. J. Wexler et al., "A randomized controlled trial of cognitive behavioral therapy for adherence and depression (CBT-AD) in patients with uncontrolled type 2 diabetes," Diabetes Care, vol. 37, no. 3, pp. 625-633, 2014.
[6] P. B. Kodali, "Mental health needs of people living with HIV/AIDS : a thematic overview," MOJ Public Health, vol. 7, no. 1, pp. 1-6, 2018.

[7] M. S. Bhatia and S. Munjal, "Prevalence of depression in people living with HIV/AIDS undergoing ART and factors associated with it," Journal of Clinical and Diagnostic Research, vol. 8, no. 10, pp. 1-4, 2014.

[8] T. Yeneabat, A. Bedaso, and T. Amare, "Factors associated with depressive symptoms in people living with HIV attending antiretroviral clinic at Fitche Zonal Hospital, Central Ethiopia: cross-sectional study conducted in 2012," Neuropsychiatric Disease and Treatment, vol. Volume 13, pp. 2125-2131, 2017.

[9] E. Kinyanda, P. Woodburn, J. Tugumisirize, J. Kagugube, S. Ndyanabangi, and V. Patel, "Poverty, life events and the risk for depression in Uganda," Social Psychiatry and Psychiatric Epidemiology, vol. 46, no. 1, pp. 35-44, 2011.

[10] A. C. Tsai, D. R. Bangsberg, E. A. Frongillo et al., "Food insecurity, depression and the modifying role of social support among people living with HIV/AIDS in rural Uganda," Social Science \& Medicine, vol. 74, no. 12, pp. 2012-2019, 2012.

[11] H. Berhe and A. Bayray, "Prevalence of depression and associated factors among people living with HIV/AIDS in Tigray, North Ethiopia: a cross sectional hospital based study," International Journal of Pharmaceutical Sciences and Research, vol. 4, no. 2, pp. 761-771, 2013.

[12] D. H. Akena, S. Musisi, and E. Kinyanda, "A comparison of the clinical features of depression in hiv-positive and hiv-negative patients in Uganda," The African Journal of Psychiatry, vol. 13, pp. 43-51, 2010.

[13] Republic FD, Federal Democratic Republic of Ethiopia Ministry of Health National Mental, 2015.

[14] S. Das and G. S. Leibowitz, "Mental health needs of people living with HIV/AIDS in India: a literature review," AIDS Care, vol. 23, no. 4, pp. 417-425, 2011.

[15] B. W. Pence, "The impact of mental health and traumatic life experiences on antiretroviral treatment outcomes for people living with HIV/AIDS," Journal of Antimicrobial Chemotherapy, vol. 63, no. 4, pp. 636-640, 2009.

[16] C. Kamen, C. Vorasarun, T. Canning et al., "The impact of stigma and social support on development of post-traumatic growth among persons living with HIV," Journal of Clinical Psychology in Medical Settings, vol. 23, no. 2, pp. 126-134, 2016.

[17] E. Martz, "Promoting self-management of chronic health conditions," Oxford Clinical Psychology, 2017.

[18] WHO, Integrating mental health into primary care: a global perspective, 2010.

[19] Ethiopia FDR of. Country progress report on the HIV, 2014.

[20] M. A. Horberg, M. J. Silverberg, L. B. Hurley et al., "Effects of depression and selective serotonin reuptake inhibitor use on adherence to highly active antiretroviral therapy and on clinical outcomes in HIV-infected patients," JAIDS Journal of Acquired Immune Deficiency Syndromes, vol. 47, no. 3, pp. 384-390, 2008.

[21] C. Castrighini, E. Gir, L. Neves, R. Reis, M. Galvão, and M. Hayashido, "Depression and self-esteem of patients positive for HIV/AIDS in an inland city of Brazil," Retrovirology, vol. 7, Suppl 1, p. P66, 2010.

[22] E. Gupta, "Unraveling the conundrum of seemingly discordant protein-protein interaction datasets," in 2010 Annual 
International Conference of the IEEE Engineering in Medicine and Biology, Buenos Aires, Argentina, September 2010.

[23] S. M. Asch, the HCSUS Consortium, A. M. Kilbourne et al., "Underdiagnosis of depression in HIV who are we missing?," Journal of General Internal Medicine, vol. 18, no. 6, pp. 450460, 2003.

[24] M. Abas, "Depression in people living with HIV in subSaharan Africa: time to act," Tropical Medicine \& International Health, vol. 19, no. 12, pp. 1392-1396, 2014.

[25] Y. Wang et al., NIH Public Access, vol. 385, no. 1, pp. 22-29, 2010.

[26] M. De Hert, C. U. Correll, J. Bobes et al., "Physical illness in patients with severe mental disorders. I. Prevalence, impact of medications and disparities in health care," World Psychiatry, vol. 10, no. 1, pp. 52-77, 2011.

[27] W. H. Day, T. World, and H. Day, mhGAP Intervention Guide - Version 2 . 0 - JUST RELEASED Psychological first aid on World Mental Health Day 2016 Continuing momentum in reforming access to care in West Africa Regional workshop on suicide prevention held in Costa Rica, 2017.

[28] P. W. Ng'ang'a, Prevalence of anxiety and depression among HIVIAIDS patients attending the comprehensive care centre (CCC), Kenyatta National Hospital (KNH), pp. 34-60, 2011.

[29] R. K. Reis, Ribeirão Preto College of Nursing, University of São Paulo, São Paulo, Brazil, E. S. Melo et al., "Prevalence and factors associated with depressive symptoms in individuals living with HIV/AIDS," Salud mental, vol. 40, no. 2, pp. 57-62, 2017.

[30] M. Slot, M. Sodemann, C. Gabel, J. Holmskov, T. Laursen, and L. Rodkjaer, "Factors associated with risk of depression and relevant predictors of screening for depression in clinical practice : a cross-sectional study among HIV-infected individuals in Denmark," HIV Medicine, vol. 16, no. 7, pp. 393-402, 2015.

[31] W. Laohasiriwong, M. Thandar, S. Boonyaleepun, and C. T. Khaing, "Prevalence of depression and its associated factors among PLHIVs attending the Public ART centers, Yangon region, Myanmar," Annals of Tropical Medicine and Public Health, vol. 10, no. 1, pp. 216-221, 2017.

[32] P. Rai and B. L. Verma, "A study on depression in people living with HIV/AIDS in South-West part of Uttar Pradesh, India," South East Asia Journal of Public Health, vol. 5, no. 1, pp. 12-17, 2015.

[33] I. B. A. O. GT, "Prevalence and correlates of depressive disorders among people living with HIV/AIDS, in north central Nigeria," Journal of AIDS \& Clinical Research, vol. 4, no. 1, 2013.

[34] J. N. Sayles, A. Pettifor, M. D. Wong et al., "Factors associated with self-efficacy for condom use and sexual negotiation among South African youth," Journal of Acquired Immune Deficiency Syndromes, vol. 43, no. 2, pp. 226-233, 2013.

[35] M. J. Rotheram-Borus, J. A. Stein, C. Jiraphongsa, S. Khumtong, S.-J. Lee, and L. Li, "Benefits of family and social relationships for Thai parents living with HIV," Prevention Science, vol. 11, no. 3, pp. 298-307, 2010.

[36] M. M. B. Mengistie, "Prevalence of depression and associated factors among HIV patients seeking treatments in ART clinics at Harar Town, Eastern Ethiopia," Journal of AIDS \& Clinical Research, vol. 6, no. 6, 2015.

[37] M. Saadat, Z. M. Behboodi, and E. Saadat, "Comparison of depression, anxiety, stress, and related factors among women and men with human immunodeficiency virus infection,"
Journal of Human Reproductive Sciences, vol. 8, no. 1, pp. 48-51, 2015.

[38] E. Kinyanda, S. Hoskins, J. Nakku, S. Nawaz, and V. Patel, "Prevalence and risk factors of major depressive disorder in HIV/AIDS as seen in semi-urban Entebbe district, Uganda," BMC Psychiatry, vol. 11, no. 1, 2011.

[39] T. Bitew, "Prevalence and risk factors of depression in Ethiopia: a review," Ethiopian Journal of Health Sciences, vol. 24, no. 2, pp. 161-169, 2014.

[40] F. H. Galvan, M. A. Burnam, and E. G. Bing, "Co Occuring psychiatric symptoms and drug dependence, heavy drinking among HIV positive people," Journal of Psychoactive Drugs, vol. 35, pp. 153-160, 2003.

[41] D. A. Eshetu and S. Meseret, "Prevalence of depression and associated factors among HIV/AIDS patients attending ART clinic at Debrebirhan Referral Hospital, North Showa, Amhara Region, Ethiopia," Clinical Psychiatry, vol. 1, no. 1, 2015.

[42] G. Tesfaw, G. Ayano, T. Awoke et al., "Prevalence and correlates of depression and anxiety among patients with HIV onfollow up at Alert Hospital, Addis Ababa, Ethiopia," BMC Psychiatry, vol. 16, no. 1, p. 368, 2016.

[43] U. E. Chikezie, A. N. Otakpor, O. B. Kuteyi, and B. O. James, "Depression among people living with human immunodeficiency virus infection/acquired immunodeficiency syndrome in Benin City, Nigeria: a comparative study," Nigerian Journal of Clinical Practice, vol. 16, no. 2, pp. 238-242, 2013.

[44] S. Okello, B. Nasasira, A. N. W. Muiru, and A. Muyingo, "Validity and reliability of a self-reported measure of antihypertensive medication adherence in Uganda," Plos One, vol. 11, no. 7, p. e0158499, 2016.

[45] A. Janežič, I. Locatelli, and M. Kos, "Criterion validity of 8item Morisky Medication Adherence Scale in patients with asthma," Plos One, vol. 12, no. 11, p. e0187835, 2017.

[46] T. Inoue, T. Tanaka, S. Nakagawa et al., "Utility and limitations of PHQ-9 in a clinic specializing in psychiatric care," vol. 12, no. 1, 2012.

[47] Y. K. Woldetensay, T. Belachew, M. Tesfaye et al., "Validation of the Patient Health Questionnaire (PHQ-9) as a screening tool for depression in pregnant women: Afaan Oromo version," PLoS ONE, vol. 13, no. 2, article e0191782, 2018.

[48] S. A. Stevelink, I. C. Wu, C. G. Voorend, and W. H. van Brakel, "The psychometric assessment of internalized stigma instruments : a systematic review," Stigma Research and Action, vol. 2, no. 2, pp. 100-118, 2012.

[49] D. Press, "Prevalence of unrecognized depression and associated factors among patients attending medical outpatient department in Adare Hospital," Neuropsychiatric Disease and Treatment, vol. 12, no. 55, pp. 2723-2729, 2016. 